\title{
Sobre o Lugar da Lógica na Sala de Aula ${ }^{1}$
}

Patrícia Del Nero Velasco ${ }^{2}$

\section{Resumo}

Sobre o lugar da lógica na sala de aula sintetiza parte da pesquisa que a autora vem desenvolvendo sobre a possibilidade de ministrar conteúdos lógicos sob um viés essencialmente informal. Por conseguinte, procura fundamentar a importância da inclusão de conceitos de lógica no Ensino Médio.

A pergunta que alguns professores de lógica fazem (como o fazem os educadores das mais diferentes áreas) diz respeito à apropriação que os alunos têm a respeito dos conteúdos ministrados: os discentes conseguem reconhecer argumentos em textos, sejam estes acadêmicos ou não? Conseguem avaliá-los? As respostas encontradas, como compartilha Alec Fisher no prefácio à primeira edição do seu A lógica dos verdadeiros argumentos (2008, p. vii), nem sempre são afirmativas.

Como muitos, esperava que o ensino da lógica ajudasse meus alunos a argumentar melhor e mais logicamente. Como muitos, fiquei decepcionado. Os estudantes que conseguiam dominar bem as técnicas da lógica pareciam convencidos de que esses não os ajudariam muito ao lidar com verdadeiros argumentos.

As páginas que seguem foram criadas, pois, na e para a sala de aula, com o intuito de amenizar a distância entre a lógica ensinada e os possíveis usos da mesma. Trata-se, contudo - e dado o espaço usual e a finalidade de um artigo - de um recorte feito na pesquisa Educando para a Argumentação: contribuições do ensino da lógica, desenvolvida pela autora desde 2003. Assim, o texto subseqüente está organizado em duas partes distintas, a saber: uma primeira parte centrada na justificativa do ensino de lógica no nível médio; a segunda parte, por sua vez, traz alguns exemplos de conceitos lógicos passíveis de serem ilustrados a partir da mídia - e, portanto, sob um viés informal e (ao menos pretensamente) didático.

\section{Da urgência e pertinência da lógica no Ensino Médio.}

A fim de defendermos a relevância do ensino da lógica no nível médio, iniciemos com um dos aspectos que a Secretaria de Educação Básica espera da disciplina Filosofia. Nas 
Orientações Curriculares Nacionais para o Ensino Médio, encontramos que ao ensino da Filosofia "caberia não apenas compreender ciências, letras e artes, mas, de modo mais preciso, seu significado, além de desenvolver competências comunicativas intimamente associadas à argumentação” (BRASIL, 2006, p. 29). Atentemo-nos à exigência, cada vez maior no cenário educacional (em todos os níveis!) do desenvolvimento de 'competências associadas à argumentação’. Sendo a lógica a área da Filosofia cujo objeto próprio de investigação é justamente a argumentação, pode-se vislumbrar a contribuição desta neste processo:

Para apreciar o valor dos métodos lógicos, é importante ter expectativas realistas acerca de seu uso. [...] A Lógica trata de justificação, não da descoberta. A Lógica fornece instrumentos para a análise do discurso; e essa análise é indispensável para a expressão inteligente de nossas próprias opiniões e para a compreensão clara das opiniões dos outros (SALMON, 2002, p. 07-08).

Conseqüentemente, entre as competências cobradas no ENEM - Exame Nacional do Ensino Médio, encontra-se a de "Relacionar informações, representadas em diferentes formas, e conhecimentos disponíveis em situações concretas, para construir argumentação consistente” ${ }^{3}$. Novamente, fica implícito que a inserção de teorias e conceitos lógicos em sala de aula pode ser de grande valia. Desde que, obviamente, apresentados sob uma orientação prática. De fato, a contextualização do arcabouço conceitual lógico e filosófico em situações cotidianas torna o mesmo não apenas mais sedutor, mas, primordialmente, didático, fecundo conferindo-lhe sentido: significado e direção.

A Lógica, outrossim, figura como uma das cinco matérias básicas (juntamente com História da Filosofia, Teoria do Conhecimento, Ética e Filosofia Geral) que constituem o eixo central a partir do qual a avaliação dos cursos de graduação em Filosofia deve ser realizada. Por conseguinte, os temas lógicos trabalhados no currículo mínimo dos cursos de graduação e cobrados como tópicos de avaliação dos futuros professores de Filosofia para o Ensino Médio passaram a ser referência para os conteúdos ministrados neste nível de ensino.

Na seção 4 do capítulo Conhecimentos de Filosofia, das Orientações Curriculares para o Ensino Médio da área de Ciências Humanas e suas Tecnologias, intitulada Conteúdos de Filosofia, encontramos "sugestões de conteúdos para aqueles que futuramente venham a preparar um currículo ou material didático para a disciplina Filosofia no ensino médio” (BRASIL, 2006, p. 36). Das 30 sugestões em questão, quatro são específicas da área da 
Lógica, a saber, os itens (2), validade e verdade; proposição e argumento; (3) falácias não formais; reconhecimento de argumentos; conteúdos e forma; (4) quadro de oposições entre proposições categóricas; inferências imediatas em contexto categórico; conteúdo existencial e proposições categóricas; e (5) tabelas de verdade; cálculo proposicional. Sobre tais conteúdos, vejamos o comentário de Ronai Pires da Rocha, na obra Ensino de Filosofia e Currículo (2008, p. 77):

[...] no caso do ensino de Filosofia, um dos pontos de estrangulamento são as habilidades e capacidades do professor diante dos conteúdos de Lógica e Argumentação [...]; a lista das orientações sugere tópicos como quadro de oposições, tabelas de verdade e cálculo proposicional; sabe-se que esses conteúdos muitas vezes sequer constam do currículo de alguns cursos de Filosofia. O tratamento desses temas nos principais manuais usados no país é muito lacunar e por vezes falho.

Vê-se que embora sejam sugeridos pela Secretaria de Educação “conteúdos de lógica e argumentação”, há uma deficiência na formação dos professores a este respeito, bem como são poucas as referências aos mesmos nos materiais didáticos. Ademais, os tópicos (quando o são) ministrados na disciplina Lógica das graduações em Filosofia costumam ser, em boa parte, formais, priorizando as sistematizações (o silogismo aristotélico, o cálculo proposicional clássico, o cálculo de predicados, entre outros). Tais sistematizações, por vez, nem sempre são acompanhadas da discussão preliminar e imprescindível acerca dos fundamentos da lógica: o que é? Do que trata? O que significa dizer que um argumento é válido? O que é um argumento e em que medida a noção de validade permeia os mais diversos sistemas lógicos? Qual a idéia informal de conseqüência e quais suas propriedades elementares?

Embora de suma importância, os conceitos lógicos subjacentes à argumentação são pouco documentados - ao menos em língua portuguesa - sob um viés não formal. Daí a proposta da pesquisa aqui compartilhada. O diferencial em relação aos livros comumente utilizados é justamente a abordagem extremamente informal, a qual passa por uma pesquisa de textos filosóficos e não filosóficos que exemplifiquem os conceitos trabalhados - como será exposto na seqüência. 


\section{Conceitos lógicos elementares: algumas exemplificações.}

\subsection{Inferência e argumento.}

É usual afirmarmos que a lógica estuda inferências e argumentos. Há, pois, a necessidade de compreendermos o que são inferências e argumentos.

Inferir é concluir, é extrair informação nova a partir de raciocínio, do encadeamento de informações disponíveis. A noção de inferência pode ser trabalhada, por exemplo, a partir da resolução de enigmas lógicos ${ }^{4}$. (Ao procurar decifrá-los, faz-se uma série de encadeamentos e, subseqüentemente, de inferências.) Pode-se, igualmente, ilustrar o processo de inferência a partir da conversa entre duas galinhas, como na tira de Fernando Gonsales (veiculada no caderno Ilustrada do jornal Folha de S.Paulo, em 05 de outubro de 2007 e abaixo reproduzida):
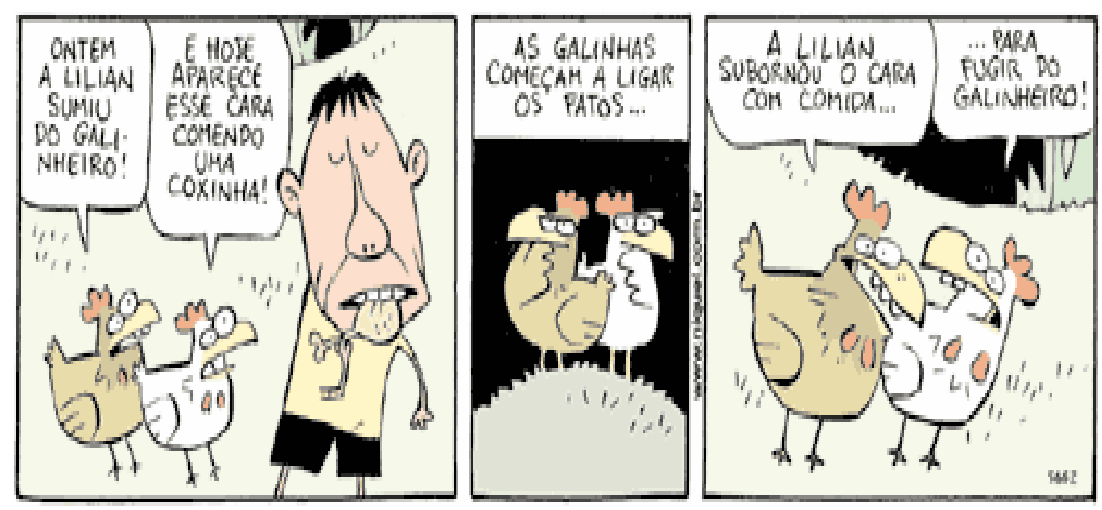

As informações disponíveis que as galinhas detinham diziam respeito ao sumiço de Lilian - uma outra galinha - e ao aparecimento de um “cara” comendo uma coxinha de galinha. A partir destes pressupostos, as galinhas da ilustração inferiram que a Lilian dera comida como suborno, garantindo a sua liberdade. Já os leitores que apreciaram a tirinha, dados os mesmos pressupostos, inferiram diferentemente, chegando à conclusão que a coxinha devorada pelo “cara” é a da própria Lilian, pobre galinha...

A partir da noção de inferência, torna-se possível conceituar premissa e conclusão. Dáse o nome de conclusão à informação que é extraída do processo de inferência. Já as informações que servem de fundamento para as inferências (ou raciocínios) são denominadas premissas: são os pressupostos disponíveis que justificam, embasam, oferecem sustento adequado para a aceitação da conclusão.

E o que vem ser um argumento? Trata-se de um conjunto encadeado de sentenças declarativas, das quais uma é a conclusão, as demais, premissas, e espera-se que as premissas justifiquem a conclusão. Nesse sentido, se a inferência é um processo mental, um argumento é 
a expressão da inferência, enunciando as hipóteses tomadas como base (premissas) e encadeando as mesmas com a informação nova dali extraída (conclusão).

Os exemplos de argumentos são inúmeros nos textos filosóficos e não filosóficos. E muitos são os tipos possíveis de estrutura argumentativa. Não cabe no escopo deste artigo discorrer sobre tal variedade. Contentemo-nos com duas ilustrações: uma filosófica; outra extraída de um artigo de jornal.

1. Fragmento (1097b 15-20) do capítulo 7 do livro I da Ética a Nicômaco, de Aristóteles:

[...] por hora definimos a auto-suficiência como sendo aquilo que, em si mesmo, torna a vida desejável e carente de nada. E como tal consideramos a felicidade, considerando-a, além disso, a mais desejável de todas as coisas, sem contá-la como um bem entre outros. [...] A felicidade é, portanto, algo absoluto e auto-suficiente.

Poderíamos, então, reconstituir a estrutura argumentativa do seguinte modo:

Premissa 1. A auto-suficiência é aquilo que, em si mesmo, torna a vida desejável.

Premissa 2. A felicidade é a mais desejável de todas as coisas.

Conclusão. A felicidade é algo absoluto e auto-suficiente.

2. Fragmento do artigo de Paulo Cobos, "Brasil de Dunga domina os vizinhos”, publicado no caderno de esportes da Folha de S.Paulo em 10 de outubro de 2007:

A seleção brasileira abriu ontem sua preparação final para uma missão que seu treinador considera até mais difícil do que uma Copa do Mundo. Mas a realidade é bem diferente da imaginada por Dunga.

O Brasil só é rei hoje, da base até o time adulto, na América do Sul [...]. Contra os vizinhos sul-americanos, a seleção jogou oito vezes, venceu sete e empatou uma. O aproveitamento é de 92\%, a média de gols pró fica em três por partida, e a defesa foi vazada só 0,57 vez por jogo. Diante de times de outras regiões, esses números são, respectivamente, $64 \%, 1,45$ e 0,91 .

Porém, a supremacia continental não é exclusividade de Dunga. O Brasil é bicampeão da Copa América, mas fracassou no Mundial. Em 
2007, ganhou os Sul-Americanos sub-17 e sub-20, mas fez campanha vergonhosa nos Mundiais dessas categorias - caiu nas oitavas-de-final na primeira e nem passou da fase inicial na segunda.

Neste caso, uma possível estruturação do argumento ficaria assim:

Premissa 1. O aproveitamento da seleção jogando contra os vizinhos sulamericanos é de $92 \%$, contra 64\% contra times de outras regiões.

Premissa 2. A média de gols pró é de 3 por partida, contra 1,45 em cada partida “fora” da América do Sul.

Premissa 3. A defesa foi vazada 0,57 vez por jogo contra sul-americanos e 0,91 vez contra outros times.

Premissa 4. O Brasil ganhou os últimos torneiros envolvendo países sulamericanos e perdeu aqueles envolvendo países de outras regiões.

Conclusão. O Brasil só é rei hoje, da base até o time adulto, na América do Sul.

Por fim, igualmente importante é auxiliar os alunos a perceberem que nem todo texto é (ou pretende ser) argumentativo. A sinopse do filme “Tropa de Elite”, escrita por Jerônimo Teixeira e publicada na reportagem “Osso duro de roer” (VEJA, São Paulo, ano 40, n 40, p. 134-137, 10 de outubro de 2007. Edição 2029) ilustra esta observação:

A história de Tropa de Elite se centra no esforço do capitão Nascimento para deixar o Bope [Batalhão de Operações Especiais da Polícia Militar do Rio de Janeiro]. Ele está para ganhar um filho e não quer mais participar de ações arriscadas. Precisa encontrar alguém que o substitua na tropa. Os melhores candidatos são os novatos Neto (Caio Junqueira) e André Matias (André Ramiro, ex-bilheteiro de cinema que também é novato na carreira de ator). O Bope aparece para os dois como uma ilha de honestidade no meio da podridão da PM convencional. Cada um dos dois aspirantes tem seus méritos e limitações. Neto gosta da dureza militar, mas é impetuoso demais, a ponto de às vezes colocar os companheiros em risco desnecessário. Matias é um homem dividido. Cursa direito em uma faculdade privada e esconde dos colegas que é policial. 
Vê-se que se trata de um texto não-argumentativo, no qual não há a possibilidade de identificação de premissas e conclusão - justamente porque as sentenças que o compõem não estão encadeadas com o intuito de fundamentar uma idéia (conclusão) com base em outras (premissas).

\subsection{Dedução e indução.}

Uma inferência, como visto, é uma conclusão extraída de um raciocínio. Um argumento, por sua vez, é a enunciação do processo de inferência. Como há diferentes modos de inferência, há, igualmente, diferentes tipos de argumentos. De acordo com o modo como a conclusão de um argumento é obtida, pode-se perguntar: trata-se de uma inferência direta ou realizada por generalização ${ }^{5}$ ? A conclusão é necessária a partir da suposta verdade da(s) premissa(s) ou é apenas provável? As respostas para tais perguntas nos oferecem a distinção entre argumentos dedutivos e indutivos - como veremos nos exemplos subseqüentes.

Analisemos, pois, dois artigos extraídos da mídia. O primeiro, “7 pecados da Dieta”, é de Monica Weinberg e foi divulgado na VEJA (São Paulo, ano 40, nº 39, p. 126-128. Edição 2028) de 3 de outubro de 2007. O segundo, por sua vez, é de Denise Mota. Intitula-se “Xingar alivia a dor, sugere estudo de psicólogo britânico” e está disponível em: http://www1.folha.uol.com.br/folha/equilibrio/noticias/ult263u629118.shtml. (Acesso em 27 de setembro de 2009.) Seguem os artigos em questão:

7 pecados da Dieta. Abusar de comida congelada light de supermercado prejudica a dieta. O número de calorias de um alimento é em geral calculado com base numa fatia e raramente na porção completa. A experiência dos consultórios mostra, no entanto, que muitas pessoas erram na conta ao tomar a parte pelo todo. Resultado: elas pensam estar diante de um prato levíssimo, quando freqüentemente se trata de uma bomba calórica.

Xingar alivia a dor. De vez em quando, vale a pena esquecer o que os pais e as aulas de boas maneiras ensinaram: em momentos de dor, xingar pode ajudar, e muito. A descoberta partiu de um estudo coordenado pelo psicólogo Richard Stephens, da Universidade Keele, na Inglaterra. Intrigado com o uso automático de palavrões como 
reação imediata ao sofrimento físico, Stephens decidiu investigar o papel das expressões ofensivas na resposta do corpo à dor. Fez um experimento com 67 estudantes: mergulhou a mão deles em um recipiente com água extremamente gelada e deixou que proferissem todos os xingamentos que quisessem. Em um segundo momento, repetiu a experiência, mas não foi permitido que falassem palavrões. Quando xingaram, resistiram por 30 segundos a mais à baixa temperatura. O estudo constatou que dizer palavrões aumenta os batimentos cardíacos e diminui a percepção da dor.

No primeiro exemplo, a conclusão (“abusar de comida congelada light de supermercado prejudica a dieta”) foi extraída do encadeamento direto das premissas: dado que o número de calorias de um alimento é em geral calculado com base numa fatia (e raramente na porção completa) e muitas pessoas em dieta tomam (erroneamente e de modo não proposital) este número baseado na fatia como referência da refeição que fazem, então se pode concluir que tais pessoas em dieta consomem "bombas calóricas” ao invés de "pratos levíssimos”, prejudicando suas dietas. Trata-se de uma conclusão necessária dada a (ainda que suposta) verdade das premissas.

No segundo exemplo, por sua vez, a conclusão (“Xingar alivia a dor”) foi extraída por generalização (o resultado observado nos 67 estudantes do experimento foi estendido às demais pessoas); por conseguinte, pode-se afirmar que provavelmente “dizer palavrões aumenta os batimentos cardíacos e diminui a percepção da dor”, mas não que isso necessariamente ocorra.

Temos assim, respectivamente, as ilustrações de um argumento dedutivo e de outro indutivo.

\subsection{Falácias não-formais.}

Etimologicamente, falácia é um argumento falho. Falácia é, pois, um argumento que contém um erro de raciocínio - baseado na invalidade, na irrelevância das premissas ou em alguma ambigüidade na linguagem. Serão apresentados (e ilustrados) na seqüência três tipos de falácias.

O argumento ad baculum ou de recurso à força (ou ainda, de apelo à força) ocorre à medida que há o apelo à força ou há a intimidação (ameaça de força) para que se estabeleça a 
conclusão desejada. "Ad baculum significa, literalmente, 'com o báculo ou porrete”” (WALTON, 2006, p. 130).

Lembremos, a título de ilustração, o argumento ad baculum proferido contra Galileu Galilei (1564-1642):

O Santo Ofício transmitiu a sua sentença à Congregação do Índex. Em 3 de março de 1616, tal Congregação emitiu a condenação do copernicanismo [segundo o qual o Sol é o centro do universo e a terra que não é o centro - se move]. Nesse meio tempo, em 26 de fevereiro, por ordem do papa, o cardeal Belarmino advertia Galileu para que abandonasse a idéia copernicana e o instava, sob pena de prisão, “a não ensiná-la e não defendê-la de nenhum modo, nem com a palavra nem com os escritos” (REALE; ANTISERI, 2004, p. 205).

Aqui o recurso à força é evidente: sob pena de prisão, Galileu foi obrigado a abjurar (o que ocorreu só em 22 de junho de 1633, data em que foi novamente interrogado e, desta vez, condenado). Impossível não observarmos que o apelo à força pode, felizmente, não ser tão persuasivo...

O cartum (ou tirinha) da série Mundo Monstro, de Adão Iturrusgarai (In: Folha de S.Paulo, Caderno Ilustrada, Quadrinhos. São Paulo, quarta-feira, 10 de setembro de 2008.), também ilustra a ocorrência de um argumento de recurso à força:
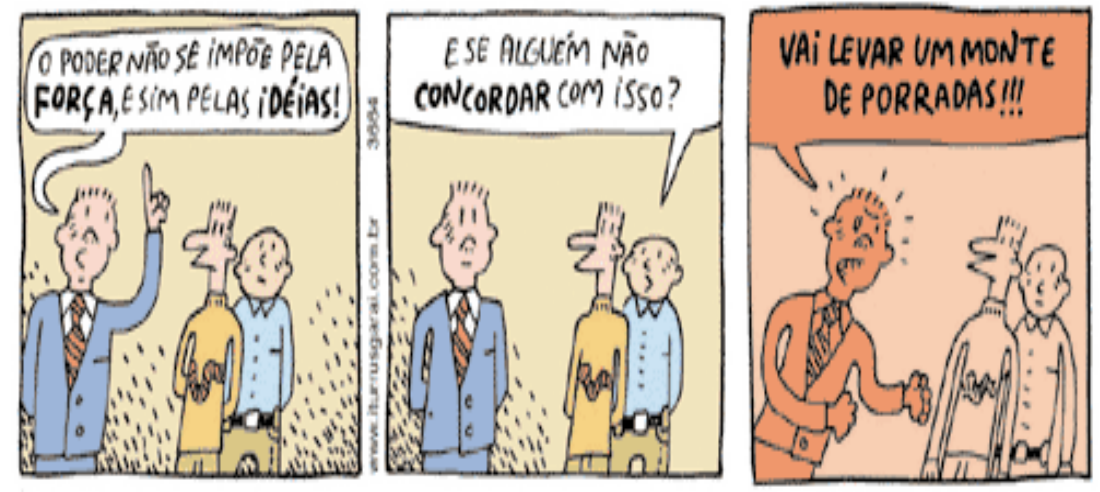

Os argumentos ad verecundiam ou falácias de apelo à autoridade, por sua vez, consistem no apelo ao respeito ou admiração por pessoas famosas para a comprovação de determinada proposição em uma área distinta daquela em que estes famosos se sobressaíram. Inúmeros exemplos podem ser extraídos dos meios publicitário e televisivo: atrizes famosas (e macérrimas) anunciam cervejas que não bebem; campeões olímpicos vendem desde carros até empreendimentos imobiliários; personalidades de Hollywood são convidadas especiais de 
mesas-redondas sobre meio-ambiente; o rei do futebol divulga cartão de crédito, operadora de celular, plano de saúde... e esponja de aço ${ }^{6}$ !

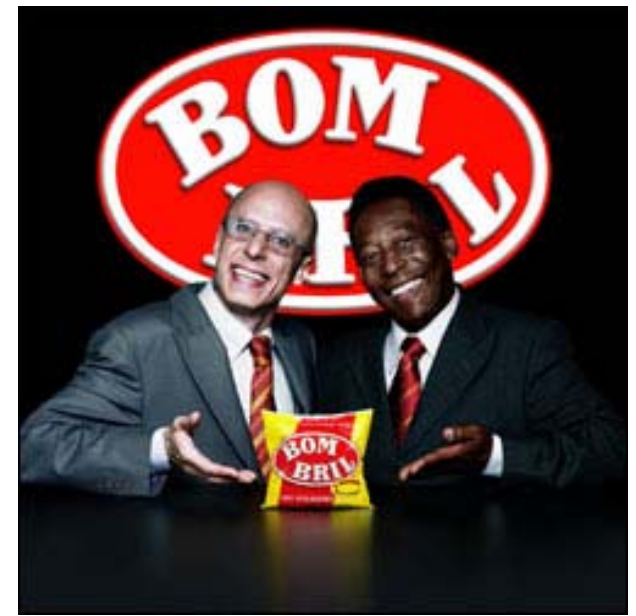

Já a falácia de equívoco consiste na não distinção dos sentidos diferentes de uma mesma palavra. Deve-se notar, todavia, que a falácia em questão é extremamente usada em propagandas e programas de humor, os quais visam justamente o riso (possível) advindo da confusão dos significados de um mesmo termo. A tira do cartunista Adão Iturrusgarai (Mundo Monstro. In: Folha de S.Paulo, Caderno Ilustrada, Quadrinhos. São Paulo, quarta-feira, 11 de outubro de 2008) atesta esta observação:

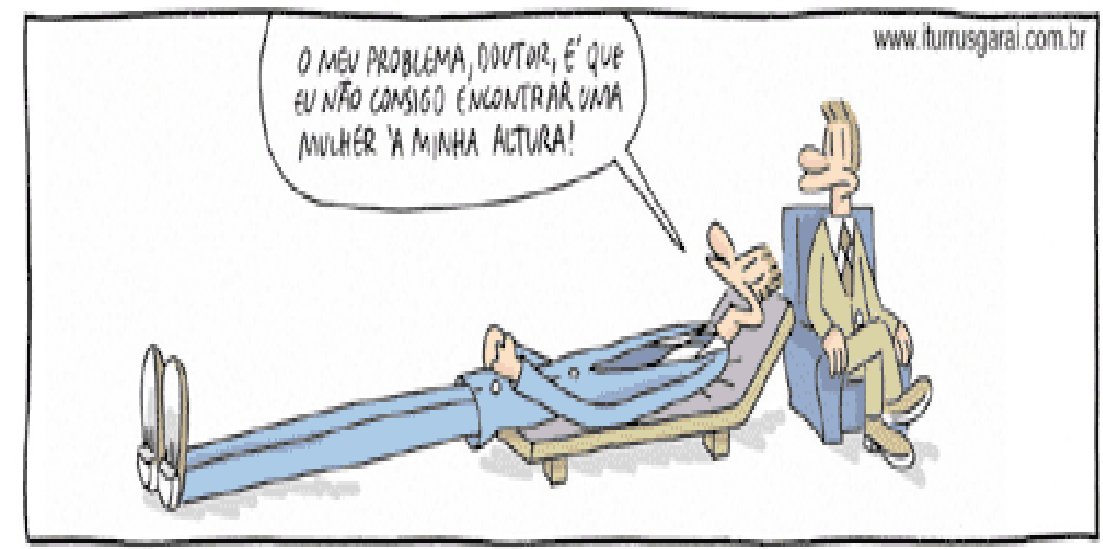

As falácias são inúmeras e os usos cotidianos, variados. Nos terrenos jurídico, publicitário, familiar, político, educacional, dentre outros, freqüentes são os argumentos falaciosos, o que torna o estudo da temática em questão extremamente atraente para alunos de todas as idades.

\section{Considerações finais}

Por fim, pode-se dizer que se inferir é o processo mental a partir do qual certas informações (ditas conclusões) são extraídas de outras (denominadas premissas), a lógica é, sem dúvida, uma ferramenta apropriada para a avaliação e aprimoramento do raciocínio, dado 
que estuda justamente as relações de conseqüência: as condições a partir das quais certas informações decorrem de outras.

Neste sentido, se o ensino da lógica não é suficiente para um pensar autônomo por parte do educando (não temos garantia disso!), ao menos pode propiciar a esse a descoberta da possibilidade de pensar sobre o próprio pensar de forma organizada e encadeada sistematizando as explicações, opiniões, crenças, etc. Por conseguinte, parece auxiliar no reconhecimento das diferentes estruturas argumentativas, permitindo àquele que se familiariza com os conceitos lógicos (ainda que elementares), um arcabouço teórico interessante tanto para a criação quanto para a avaliação crítica de argumentos.

É preciso saber reconhecer aqueles pontos críticos em que o diálogo deixa de ser racional ou se afasta de uma linha melhor de argumentação. Na verdade, saber reconhecer esses pontos e saber lidar com eles através do questionamento crítico correto são habilidades fundamentais da lógica informal como disciplina (WALTON, 2006, p. 33).

Julgamos, pois, que a lógica é uma das ferramentas intelectuais a que Lorieri faz menção quando afirma “(...) cabe-lhes (às crianças e jovens) o direito de aprender a dominar o uso das ferramentas intelectuais que lhes possibilitem as decisões” (2002, p. 43). Ademais, como salienta Gustavo Bernardo na obra Educação pelo argumento (2000), “A ênfase no argumento chama a atenção para a necessidade do diálogo com o outro e, por via de conseqüência, para a necessidade do argumento que oriente, de maneira civilizada (sem o que, para que? - o porrete seria suficiente), todo diálogo, todo debate, toda discussão” (BERNARDO, 2000, p. 12). Fica então a proposta para um novo artigo: buscar as fundamentações das possíveis relações entre argumentação e civilidade.

\section{Referências Bibliográficas}

BERNARDO, Gustavo. Educação pelo argumento. Rio de Janeiro: Rocco, 2000.

BRASIL. Ministério da Educação. Secretaria de Educação Básica. Ciências humanas e suas tecnologias / Orientações curriculares para o ensino médio; volume 3. Brasília: MEC/SEB, 2006.

Da COSTA, Newton C. A. Lógica indutiva e probabilidade. São Paulo: Hucitec: Editora da Universidade de São Paulo, 1993. 
FISHER, Alec. A lógica dos verdadeiros argumentos. Tradução de Rodrigo Castro. São Paulo: Novo Conceito Editora, 2008.

LORIERI, Marcos Antonio. Filosofia: fundamentos e métodos. São Paulo: Cortez, 2002. (Coleção Docência em Formação)

NOLT, John; ROHATYN, Dennis. Tradução de Mineko Yamashita; revisão técnica de Leila Zardo Puga. São Paulo: McGraw-Hill, 1991. - (Coleção Schaum)

REALE, Giovanni; ANTISERI, Dario. História da filosofia: do humanismo a Descartes. Vol. 3. Tradução de Ivo Storniolo. São Paulo: Paulinas, 2004.

ROCHA, Ronai Pires da. Ensino de Filosofia e Currículo. Petrópolis, RJ: Vozes, 2008.

SALMON, Wesley C. Lógica. Tradução de A. Cabral. Rio de Janeiro: LTC, 2002.

WALTON, Douglas. Lógica informal. Tradução de A. L. R. Franco e C. A. L. Salum. São Paulo: Martins Fontes, 2006.

\footnotetext{
${ }^{1}$ O presente texto foi apresentado no II Encontro Nacional do GT da ANPOF: Filosofar e Ensinar a Filosofar, promovido pelo Programa de Pós-Graduação em Filosofia da Universidade Gama Filho e realizado nos dias 10 e 11 de setembro de 2009, no Rio de Janeiro.

2 Professora da Universidade Federal do ABC (UFABC-São Paulo). Correio eletrônico: patricia.velasco@ufabc.edu.br

${ }^{3}$ Disponível em 〈http://www.enem.inep.gov.br/index.php?option=com content\&task=view\&id=18\&ltemid=28〉.

Acesso em 17 mar. 2008.

${ }^{4}$ Sugere-se, por exemplo, a obra Alice no país dos enigmas (2000), do lógico e matemático Raymond Smullyan. Nesta, o autor recria o universo de Lewis Carroll, envolvendo as personagens de Alice no país das maravilhas e Alice através do espelho em situações que exigem do leitor o uso do raciocínio lógico para entender o encadeamento e o desdobramento das várias histórias.

${ }^{5}$ A despeito da falta de rigor na associação simples entre indução e generalização (cf. Da Costa, 1993), assim o faremos nesta seção por tomarmos como base o conceito amplamente difundido nos livros introdutórios ao assunto (cf., por exemplo, Nolt e Rohatyn (1991) e Salmon (2002)).

${ }^{6}$ Campanha publicitária "Pelé é 10", criada pela agência W/Brasil para a BOMBRL. Disponível em comunicadores.info/2007/04/28/bombril-eterno/ .Acesso em: 05 de junho de 2009.
} 